\title{
Quantitative Contribution of Climate Change and Land Use Change to Runoff in Tarbela Catchment, Pakistan
}

\author{
Rana Shahram Shaukat', Mudasser Muneer Khan', Muhammad Shahid ${ }^{2,3 *}$, \\ Muhammad Shoaib ${ }^{4}$, Tanveer Ahmad Khan', Muhammad Asif Aslam ${ }^{1}$
}

\author{
${ }^{1}$ Department of Civil Engineering, University College of Engineering and Technology, Bahauddin Zakariya University, \\ Multan, Pakistan \\ ${ }^{2}$ State Key Laboratory of Hydroscience and Engineering, Department of Hydraulic Engineering, Tsinghua University, \\ Beijing, China \\ ${ }^{3}$ NICE, SCEE, National University of Sciences and Technology, Islamabad, Pakistan \\ ${ }^{4}$ Department of Agricultural Engineering, Bahauddin Zakariya University, Multan, Pakistan
}

Received: 6 July 2019

Accepted: 8 September 2019

\begin{abstract}
Estimating the quantitate contribution of climate and land use change is necessary for planning water resources. Tarbela catchment in Pakistan was selected for this study. The Mann Kendall and Pettit test has been used for trend analysis of hydro climatic variables. Original climate elasticity method and improved empirical model of precipitation have been used. The results of trend analysis showed that precipitation and runoff trends decreased and potential evaporation trends increased. The annual rainfall and runoff presented a change point around the years 1999 and 1994 respectively. According to change point analysis, the runoff series was divided into two parts. The period before change point has been regarded as the pre-change period and the period after change point has been regarded as the post change period. According to the original climate elasticity method, the relative contribution of climate change and land use change has been computed as $39.3 \%$ and $60.7 \%$ respectively. Similarly the improved empirical model of precipitation showed relative contributions of climate change as $41.7 \%$ and the same for land use change as $58.3 \%$. To validate the land use change contribution we prepared land use maps. It can be concluded that land use and climate change are responsible for runoff change in Tarbela catchment, and both methods performed well and results are in agreement.
\end{abstract}

Keywords: runoff change, attribution, climate change, Tarbela dam, Pakistan, water resources

*e-mail: heid15@mails.tsinghua.edu.cn 


\section{Introduction}

Water is the most important element for all living things. During the past few decades water scarcity has become a global challenge [1-2]. The World Economic Forum report of 2015 identified the water crises as the first high-impact risk for current times. The International Hydrological Program focuses on water security and its availability on regional and global scales, and addressing water scarcity and quality is its sixth theme. Runoff is the main source of water availability for our environment and it is produced by the interaction of climate change and land use change [3]. The spatial distribution of runoff changes due to climate change as it changes the spatial and temporal distribution of precipitation. It has been concluded in different research studies that precipitation and temperature patterns of different regions have been changed due to alterations in the hydrological cycle that have occurred due to land use. The increasing temperature also changes the distribution of runoff [4], and as has been observed during the past few decades, global temperature has increased significantly [5]. Similarly, land use changes directly affect the process of flow generation, which significantly changes runoff [6]. Researchers have concluded that half of the global surface and subsurface water has been used by humans, and due to a recent increase in agriculture and industrial activities this demand is increasing day by day [7]. Land use changes are mainly due to human activities in a basin, which directly affect the flow mechanism of a river. Due to land use changes and human activities in source areas, the flow decreases in upper and middle reaches of a basin, which directly impacts the runoff regime in lower parts of the basin and cause water shortage $[8,9]$. Human and development activities in a catchment area change the regime of runoff by affecting the infiltration capacity. The size and peek of flood wave is also land use sensitive, and land use changes also impact flood timings. However, the impact of these land use changes vary at the regional level [10-12]. Moreover, the quantification of relative contribution of the climate change and land use change impacts on runoff generation is important for arid and semi-arid regions [13]. Therefore, understanding the hydrological cycle is important at the regional level.

Globally, many studies have been performed to understand the impact of land use change and climate change on runoff generation, and various methods have been adopted [14-18]. These methods include hydrological modeling, statistical techniques and paired catchment techniques. All these methods have merits and demerits. For example, the hydrological modeling method uses mostly distributed, lumped and dynamic models. The calibration and validation of these methods requires a large number of datasets, which is why it is hard to use them in a basin with limited information. However, the uncertainties and discrepancies exist in results of every method and model. The empirical methods have been proposed for attribution purposes and these methods test sensitivity of streamflow to climate change. The empirical methods have been used in different parts of the world and such methods have been found to be very helpful for runoff attribution [19-20]. The empirical method provides physical interpretation and has fewer data requirements. Therefore, such methods are referred to developing countries that have fewer resources to monitor the hydrological data. Different researchers have performed studies on the Indus River basin and concluded that flow changes are due to temperature and global climate change projections. The results also suggest that the impact of land use and climate changes have a serious impact on future water resources of Pakistan's water resources [21]. Tarbela dam is the first regulatory storage on the River Indus and the maximum of the annual Upper Indus River inflow stored at Tarbela. Tarbela Dam is the main source of water for Pakistan. Agricultural productivity is very dependent on this reservoir. Moreover, the power supply of the country is also dependent on this reservoir. This is the first attempt to understand the impact of climate and land use change in the Indus basin - especially Tarbela Catchment. Accordingly, this study presents and compares the results from two statistical methods: the original climate elasticity method and improved empirical model of precipitation method to evaluate the runoff change in Tarbela Catchment. The land use change and climate change impacts are considered as independent in the present study. The independent consideration of both factors has been used in previous

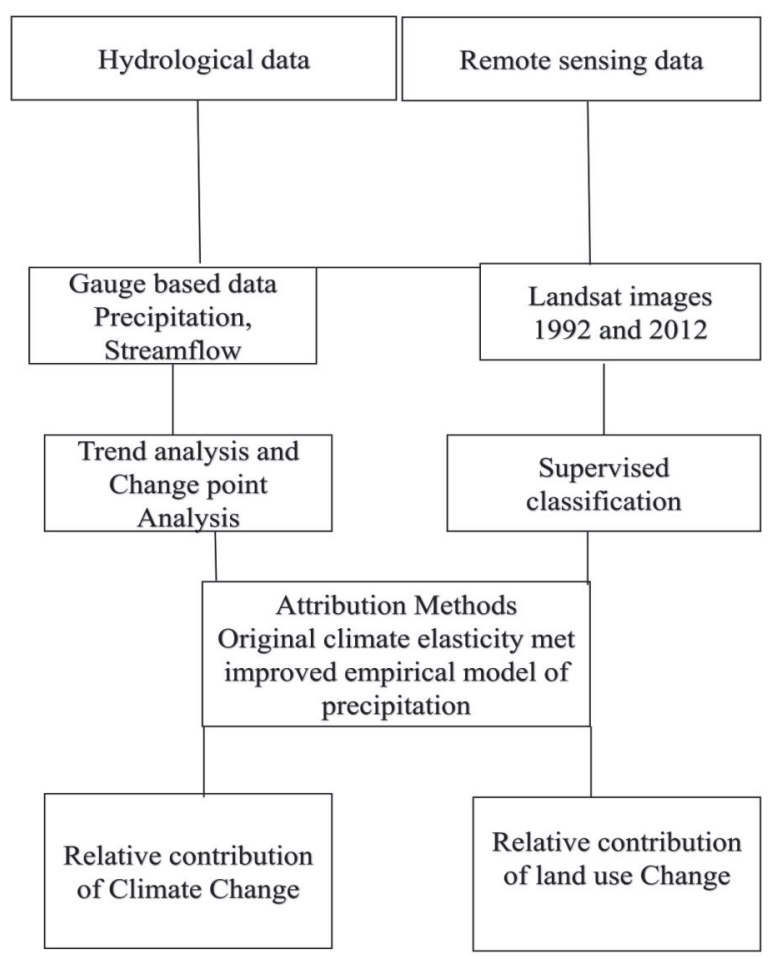

Fig. 1. Methodology of the study. 
studies [22-23]. The methodology adopted in this study is given in Fig. 1. The objectives of this study are: (1) to understand hydrological trends in Tarbela Catchment and (2) to evaluate the impacts of land use change and climate change on Tarbela inflow.

\section{Material and Methods}

\section{Study Area}

Pakistan is one of the most important countries of South Asia; mostly Pakistan is arid. The population of Pakistan is growing rapidly, which places stress on the natural resources of the country. Pakistan is among the water stressed countries now, per capita water is less than $1000 \mathrm{~m}^{3} /$ year, and it is the seventh most vulnerable country in terms of climate change [24]. Tarbela dam is the main source of water supply to Pakistan. Agricultural productivity is very dependent on this reservoir. Moreover, the power supply of the country is also dependent on the catchment area of Tarbela Dam, which is shown in Fig. 2. The catchment area has been delineated by using Aster global digital elevation model and the catchment area of Tarbela is calculated as $162393 \mathrm{~km}^{2}$. The mean elevation of the catchment is $4750 \mathrm{~m}$, and $60 \%$ of this area has elevation of $4500 \mathrm{~m}$ and $12 \%$ of this area has an elevation of $5500 \mathrm{~m}$. The climate varies from north to south according to the latitude of the study area. The climate changes from subtropical to colder. The average rainfall varies between $950 \mathrm{~mm}$ in the south to $1500 \mathrm{~mm}$ in the north. The trend of rainfall is monsoonal, the rainfall in the winter and autumn is more important. The rainfall in these seasons is effective due to lower temperatures. The rainfall in summer and spring seasons is torrential, and during this season the temperature remains high. Summer season varies from hot to very hot. The geology of Tarbela catchment area is loosely cemented sandstone and friable sandy shale. The soil here is sand, silt and clay. The physiography of the catchment area is hilly, with hills ranging between elevations of $500 \mathrm{~m}$ at the western end to $2200 \mathrm{~m}$ on its eastern end, which has an average height of $1000 \mathrm{~m}$.

\section{Data Description}

Hydrological and meteorological data were collected for this study. The flow data was collected for Tarbela gauging stations of the surface water hydrology project section of the Water and Power Development Authority during 1980-2012. Then obtained data of streamflow was aggregated into annual mean and converted in (mm) [25].

$$
\operatorname{DISCHARGE}\left(\frac{m m}{\text { day }}\right)=\frac{\text { Discharge }\left(m^{3} / s\right) *(3600 * 24)}{\text { Watershedarea }\left(m^{2}\right) * 1000}
$$

Meteorological data including rainfall and temperature of different stations was collected during 1980-2012. Daily climatic data was collected from

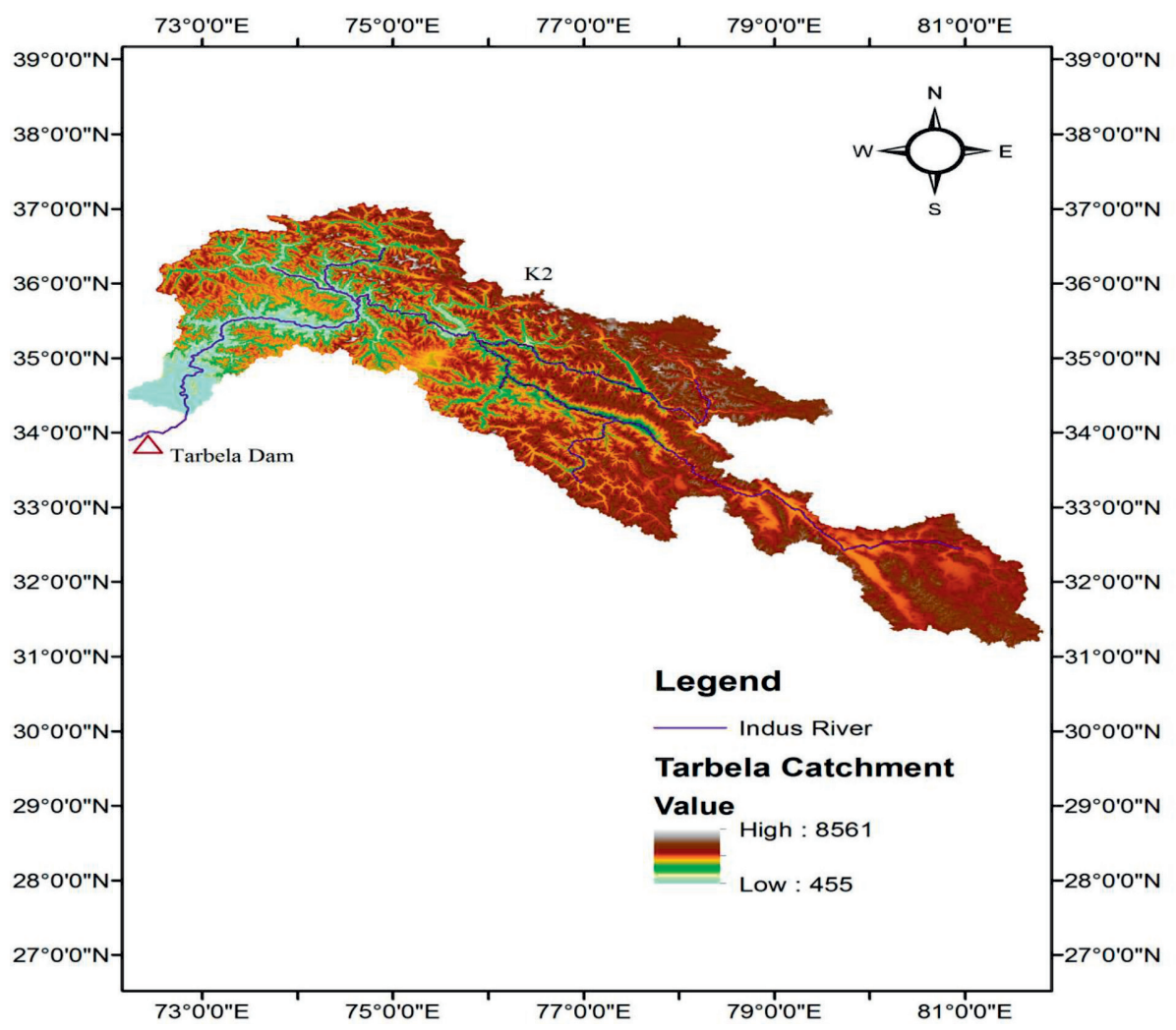

Fig. 2. Catchment area of Tarbela Dam. 
Astore, Gilgit, Gupis, Garhi dupatta, Darosh, Dir, Dhanyor, Saidu, Kotli, Muzafferabad, and Murree meteorological stations. The Pakistan Meteorological Department (PMD) stations are mostly at lower elevations, and only few stations of (PMD) measure climate data at higher elevation. The Glacier Monitoring Research Centre (GMRC) of WAPDA has installed stations at higher elevations, so we selected the (GMRC) stations with maximum duration and suitable condition for this study. Potential evapotranspiration (PET) is calculated by Penman equation using FAO guidelines. Inverse distance weighted method is used to estimate areal values, while potential evaporation and daily precipitation are spatially averaged across the study area. From a survey of Pakistan we obtained topographical information. Stream network and catchment boundaries are delineated on the basis of a digital elevation model.

\section{Change Point and Trend Test Identification}

There are many tests for trend detection, but a nonparametric test is preferred [26-27]. To detect trends in hydro-climatic variables, the Mann-Kendall test is mostly used [24]. The Mann-Kendall and Pettit change point tests have been used to identify trends and shifts in mean of time series. The MK test has two advantages, first it is a non-parametric test and normal distribution of data is not required. Secondly, in homogeneous data series this test is very sensitive to abrupt changes. In the MK test, the null hypothesis is represented by $\mathrm{H} 0$ and it is assumed that no trend is present in data series and that data is ordered independently. This null hypothesis is evaluated against an alternative hypothesis H1. In this alternative hypothesis $\mathrm{H} 1$ it is supposed that a trend is present in the data series. The calculation procedure of MK test includes the time series with $n$ data points. Moreover, it also includes two sub data sets named $\mathrm{Ti}$ and $\mathrm{Tj}$. Where $\mathrm{i}=1,2,3, \ldots, \mathrm{n}-1$ and term $\mathrm{j}=\mathrm{i}+1, \mathrm{i}+2$, $\mathrm{i}+3, \ldots, \mathrm{n}$. The values present in data series are checked as they are ordered. Every data set is equaled with the subsequent data values. If the data sets in a later series are more than the data sets of an earlier time the value of $\mathrm{S}$ is increased by one. Similarly, if the data sets in a later series are lower as compared to earlier series, the $\mathrm{S}$ is decreased by one. The final value of the statistic $\mathrm{S}$ is computed from all these increments and decrements. The equation for Mk statistic $\mathrm{S}$ is:

$$
\begin{gathered}
S=\sum_{i=1}^{n-1} \sum_{j=i+1}^{n} \operatorname{sgn}\left(T_{j}-T_{i}\right) \\
\operatorname{sgn}\left(T_{j}-T_{i}\right)= \begin{cases}1 & \text { if }\left(T_{j}-T_{i}\right)>0 \\
0 & \text { if }\left(T_{j}-T_{i}\right)=0 \\
-1 & \text { if }\left(T_{j}-T_{i}\right)<0\end{cases}
\end{gathered}
$$

$\ldots$ where $T_{j}$ and $T_{i}$ are the annual values for years $\mathrm{j}$ and $\mathrm{i}$ respectively. If in the data sets $\mathrm{n}<10$, the computed value for $|\mathrm{S}|$ is directly equal to the theoretical value of the term $\mathrm{S}$, which is derived from the MK test. The test with two tails is used. If the calculated value of $S$ equals or is increased from the specified value of $\mathrm{S} \alpha / 2$, the value of $\mathrm{HO}$ is rejected for the term $\mathrm{H} 1$. If there is no trend the $S \alpha / 2$ is the least $S$ and it has a probability of less than $\alpha / 2$. The trend will be upward if term $S$ has a positive value while the trend will be downward if term $S$ has a negative value. If $\mathrm{n} \geq 10$, term $S$ is about normally distributed and it is represented as: $E(S)=0$ and the variance for $\mathrm{S}$ can be given as:

$$
\sigma^{2}=\frac{n(n-1)(2 n+5)-\sum T_{i}(i)(i-1)(2 i+5)}{18}
$$

In this equation, term ti shows the ties up to the $\mathrm{i}$. Zs is computed by using following equation:

$$
Z_{s}= \begin{cases}\frac{S-1}{\sigma} & \text { if }[S>0] \\ 0 & \text { if }[S=0] \\ \frac{S+1}{\sigma} & \text { if }[S<0]\end{cases}
$$

The significance in trend is evaluated by using the statistic Zs. This statistic is used to check the H0, which is null hypothesis. The null hypothesis is not valid if the value of $|Z s|$ is greater compared to the value of $\mathrm{Z} \alpha / 2$. Term $\alpha$ shows the selected significance level. If null hypothesis is not valid the trend will be considered as a significant trend and vice versa. There is another statistic Kendall's tau which is obtained during the MK test. Kendall's tau is used to calculate the correlation and it finds the power of relationship among the two variables that are tested. Kendall's tau is based on data ranks for every variable and the values are ordered and then numbered. The lowest value is numbered as 1 and the next lowest value is numbered as 2 and so on. In data analysis is crucial to consider the serial correlation of data sets. Autocorrelation enhances the chances for detection, therefore modified Mann-Kendall test is used and the adjusted variation is computed by:

$$
\operatorname{Var}[S]=1 / 18[N(N-1)(2 N+5)] N /\left(N S^{*}\right)
$$

...where

$$
N /\left(N S^{*}\right)=1+\frac{2}{N(N-1)(N-2)} \sum_{i=1}^{p}(N-i)(N-i-1)(N-i-2) \operatorname{Ps}(i)
$$

In this equation $\mathrm{N}$ represents the observation numbers, the term NS* represents the effective number of observations, and $\rho_{\mathrm{s}}(\mathrm{i})$ represents the 
ranks autocorrelation. This test is performed by using XLSTAT 2012 and Microsoft Excel is used for graphical interpretation. The Pettit test is used to find a single change point in hydrological and climatological data series. Pettit test hypothesis H0 says for the variable $\mathrm{T}$ with one or more distributions having the same parameter locations. The non-parametric statistic is represented as $\mathrm{K}_{\mathrm{T}}=\max \left|\mathrm{U}_{\mathrm{t}}, \mathrm{T}\right|$, where:

$U_{t}, T=\sum_{i=1}^{t} \sum_{j=t+1}^{T} \operatorname{sgn}\left(X_{i}-X_{j}\right)$ and $\rho \cong 2 \exp \left(\frac{-6 K_{T}^{2}}{T^{3}+T^{2}}\right)$

This test does not require any assumption regarding distribution of the data sets. It is an adaptation of the tank-based Mann Whitney test.

\section{Attribution of Runoff Change}

Due to intensive human activities, the runoff series shows an abrupt change point. The runoff series before the abrupt change point is considered a base line. Before and after change point contains two parts: one is change in runoff due to human activities and the second is change in runoff due to climate change. In quantitative attribution methods the hydrological mode is calibrated before the change point period and then employed after the change point period. The runoff attribution from this method can be expressed using the following equations:

$$
\begin{gathered}
\Delta \mathrm{WT}=\mathrm{WHR}-\mathrm{WB} \\
\Delta \mathrm{Wh}=\mathrm{WHR}-\mathrm{WHN} \\
\Delta \mathrm{WC}=\mathrm{WHN}-\mathrm{WB} \\
\mathrm{nH}=\Delta \mathrm{WH} \Delta \mathrm{WT} \times 100 \% \\
\mathrm{nC}=\Delta \mathrm{WC} \Delta \mathrm{WT} \times 100 \%
\end{gathered}
$$

...where the change in total runoff is expressed by $\Delta \mathrm{WT}$, the change in runoff due to human activities is represented by $\Delta \mathrm{WH}$ and change in runoff due to climate change is expressed as $\Delta \mathrm{WC}$ respectively. The runoff in baseline period is expressed by WB and the runoff after change point (which is regarded as recorded runoff) is expressed as WHR, and runoff simulated after change point is regarded as natural runoff expressed as WHN. The terms $\eta \mathrm{H}$ and $\eta \mathrm{C}$ show the relative contribution due to land use change and climate change to the total runoff series respective.

\section{Original Climate Elasticity Method}

Runoff $(\mathrm{Q})$ can be written as a function of climatic variables (C) and land use characteristics (H) as: $\mathrm{R}=\mathrm{f}(\mathrm{C}, \mathrm{H})$. In this equation term $\mathrm{H}$ shows the combined impact of terrain, soil, land use and human- induced impacts (i.e., artificial water transfer projects). The soil properties and topography of the area remains unchanged for the study period as these properties need enough time to get changed, so term $\mathrm{H}$ is regarded as change in runoff due to human activities and it can be expressed as:

$$
\Delta R=\Delta R C-\Delta \mathrm{RH}
$$

... where the term $\Delta R$ represents the total change in runoff series, $\triangle R C$ represents the change in runoff due to climate change and $\Delta R H$ represents the change in runoff due to land use change/ human activities. $\Delta R$ is computed as:

$$
\Delta R=R_{\text {Observed } 1}-R_{\text {observed } 2}
$$

...where $R_{\text {Observed } 1}$ represents the measured runoff before change point period and $R_{\text {Observed } 2}$ represents the measured runoff after the change point. Schaake first used the climate elasticity method to find runoff sensitivity due to climate change. The elasticity of climate to runoff $(\mathrm{X})$ can be expressed as proportional change of runoff $(\mathrm{R})$ relative to climatic averrable, i.e., precipitation potential evapotranspiration change as: $\varepsilon_{X}=\frac{\delta R / R}{\delta X / X}$. Long-term water balance equation $\mathrm{R}=\mathrm{P}-\mathrm{E}$, where $\mathrm{R}$ represents runoff and $\mathrm{P}$ represents precipitation and $\mathrm{E}$ represents evaporation. According to the theory of total differential equation:

$\Delta R_{C}=\varepsilon_{p} \frac{R}{P} \Delta P+\varepsilon_{E_{0}} \frac{R}{E_{0}} \Delta E_{0}$ and $\varepsilon_{p}+\varepsilon_{E_{0}}=1$

...where $\Delta R_{C}$ represents the change in runoff due to climatic factors, $\Delta P$ and $\Delta E_{0}$ represent the change in precipitation and potential evapotranspiration and $\varepsilon_{p}$ and $\varepsilon_{E_{0}}$ are precipitation and potential evapotranspiration potential elasticities of runoff. According to the Budyko framework, actual evaporation $\mathrm{E}$ is a function of dryness index as represented by:

$$
\phi=\frac{E O}{P}
$$

Specifically:

$$
E=P \cdot F(\phi)
$$

Precipitation and potential evapotranspiration elasticity are expressed as:

$$
\varepsilon_{p}=1+\frac{\phi F^{\prime}(\phi)}{1-F(\phi) \varepsilon_{E_{0}}}=-\phi F^{\prime}(\phi) /(1-F(\phi))
$$

The terms $F^{\prime}(\phi)$ and $F^{\prime}(\phi)$ can be calculated using the Budyko hypothesis as mentioned in Table 1. The Zhang formula can be calibrated to find the value of constant for land use characteristics. 
Table 1. Different formulae for the Budyko hypothesis.

\begin{tabular}{|c|c|c|}
\hline Expression & $F(\phi)$ & $F(\phi)$ \\
\hline Turc (1954); Pike (1964) & $\left(1+\phi^{-2}\right)^{-0.5}$ & $1 /\left[\phi^{3}\left(1+\left(\frac{1}{\phi}\right)^{2}\right)^{1.5}\right]$ \\
\hline Zhang (2001) & $(1+\omega \phi) /(1+\omega \phi+1 / \phi)$ & $\frac{\omega+\frac{2 \omega}{\phi}-1+\frac{1}{\phi^{2}}}{\left(1+\omega \phi+\frac{1}{\phi}\right)^{2}}$ \\
\hline
\end{tabular}

\section{Improved Empirical Model of Precipitation}

The empirical model only takes precipitation as a climatic factor. The equation for the improved empirical model can be expressed as:

$$
Q_{k}=a\left(\frac{P_{k}}{P E_{k}}\right)^{b}+c
$$

In this equation $\mathrm{Q}$ represents runoff, $\mathrm{P}$ represents precipitation and $\mathrm{PE}$ represents the potential evapotranspiration $\mathrm{k}$, meaning the $\mathrm{kth}$ year of runoff. The terms $\mathrm{a}, \mathrm{b}$ and $\mathrm{c}$ are constants calculated by employing rainfall, runoff and potential evapotranspiration in the natural period. Using rainfall, runoff and potential evapotranspiration and equation above runoff $\mathrm{Q}$ is simulated. The $Q$ sim simulated runoff in the change period can be regarded to include climate change for change period while holding human impacts in the natural period. The difference of observed and simulated runoff will give a contribution of human activities during change period. The impact of climate change and human activities can be assessed as:

$$
\begin{gathered}
C_{C}=\frac{\Delta \mathrm{Q}_{C}}{\Delta \mathrm{Q}} \times 100 \%=\frac{\left|\overline{Q_{\text {sim }}}-\overline{Q_{\text {nat }}}\right|}{\Delta Q} \times 100 \% \\
C_{H}=\frac{\Delta \mathrm{Q}_{H}}{\Delta \mathrm{Q}} \times 100 \%=\frac{\left|\overline{Q_{\text {sim }}}-\overline{Q_{\text {imp }}}\right|}{\Delta Q} \times 100 \% \\
\Delta Q=\Delta \mathrm{Q}_{C}+\Delta \mathrm{Q}_{H}
\end{gathered}
$$

...where terms $C_{c}$ and $C_{H}$ show the climate change impact and human activities, and terms $\Delta \mathrm{Q}_{C}$ and $\Delta \mathrm{Q}_{H}$ show the average change in runoff due to climate and human activities.

\section{Land Use Classification}

Land use classification has been performed and land use maps of the study area have been developed to validate the contribution of land use change to runoff change. The Landsat images of 1992 and 2012 have been downloaded and processed to get the land use maps of the study area. There are different methods to classify the land use images we used and the supervised classification method to develop the land use images of the study area. The land use maps of 1992 and 2012 represent the land use situation of the study area before and after change point respectively. One-hundred training samples have been used for each class during the supervised classification method. The accuracy of classification has been performed by using the stratified random method. Ground truthing has been performed to validate 200 points. The validation has been performed by visual interpretation, and classification results are compared with the reference data by developing an error matrix. The kappa coefficient value is refereed to explain the classification results as it represents the agreement between classified data and actual ground data. Readers interested in detailed descriptions of the land use classification methods are referred to [28-29].

\section{Results and Discussion}

\section{Trend Analysis of Runoff and Climate Variables}

The Mann Kendal test was performed by using freely available software XLSTAT 2014. The test was performed for precipitation, potential evapotranspiration and runoff. The results of Mann-Kendal test are presented in Table 2. It can be observed that the precipitation trends are decreasing in the Tarbela catchment. The decreasing rate was calculated using linear regression and it is observed that the change rate for precipitation is $0.56 \%$, which shows that there is a significant decrease in rainfall of the Tarbela catchment. The results of the Mann Kendal test for potential evapotranspiration shows that there is a significant increase in potential evapotranspiration of

Table 2. Trend analysis Results for annual runoff and climate variables (mm/year).

\begin{tabular}{|c|c|}
\hline Variable & Test Statistics \\
\hline Precipitation(P) & $5.3(0.56 \%)^{*}$ \\
\hline (PET) & $4.2(0.95 \%)$ \\
\hline Runoff & $4.8(1.27 \%)^{*}$ \\
\hline
\end{tabular}

Note: *indicates trend decrease at significance levels of 0.05 . Slope is calculated by using linear regression. Change rate is shown in brackets 
Table 3. Changes in hydro-climatic variables $(\mathrm{mm} / \mathrm{a})$ between periods I (P-I) and II (P-II).

\begin{tabular}{|c|c|c|c|}
\hline & \multicolumn{3}{|c|}{ Relative Change of hydro-meteorological } \\
variables \\
\hline $\begin{array}{c}\text { Climatic } \\
\text { Variables }\end{array}$ & Period-I(P-I) & Period-II(P-II) & R- $\Delta(\%)$ \\
\hline Q (mm) & 434.60 & 337.87 & -22.26 \\
\hline P (mm) & 1036.40 & 910.51 & -12.15 \\
\hline Ep (mm) & 423.14 & 454.35 & 7.38 \\
\hline
\end{tabular}

Note: $\mathrm{R}-\Delta$ represents the relative change.

the Tarbela catchment. It can be observed from Table 2 that the decreasing rate for potential evapotranspiration is $0.95 \%$. Similarly, the results of the Mann Kendal test for runoff series shows that there is a significant decreasing trend in the runoff series. The decreasing rate is significant and the decreasing rate for Tarbela catchment is $1.27 \%$.

According to the petit test results, the runoff, rainfall and potential evapotranspiration series are divided into two periods. The relative decrease of runoff, rainfall and potential evapotranspiration for periods I and II are presented in Table 3 and show that the relative decrease for streamflow during periods I and II is $22.26 \%$. The relative decrease for rainfall during periods I and II is $12.15 \%$, and the relative increase for potential evapotranspiration during periods I and II is 7.38.

\section{Change Point Results}

The Petit test is to check the homogeneity of hydro climatic series. It is the most used test in hydrology and can tell us that if there is any inhomogeneity in the series of variable. The Pettit test was performed on rainfall, runoff and Potential evapotranspiration series of Tarbela catchment. The results of the Petit test for runoff, potential evapotranspiration and rainfall series are presented in Figs 3-5. It can be observed that for annual rainfall series there is a change point around the year 1999. Moreover, for potential evapotranspiration series there is a change point around 2008. Similarly, for runoff series there is a change point around 1994. As we are much concerned to evaluate the decrease in runoff, the change point for runoff series is around 1994. For comparison and better understanding, we have divided the variable series into two periods. Period I is from 1980-1994 and period II is from 1995-2012. Such a division of variable series using the petit test is acceptable and practiced in literature [30-31].

\section{Attribution Results}

The original climate elasticity method and improved empirical model of precipitation, PE and runoff were selected to perform runoff attribution. The Zhang

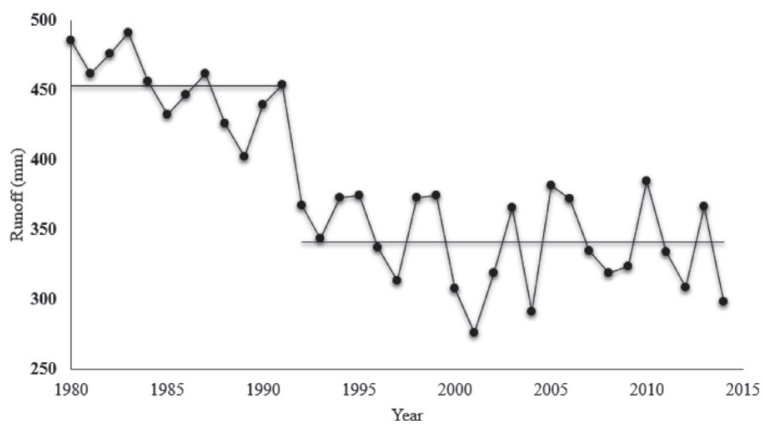

Fig. 3. Pettit test for annual runoff data of Tarbela catchment.

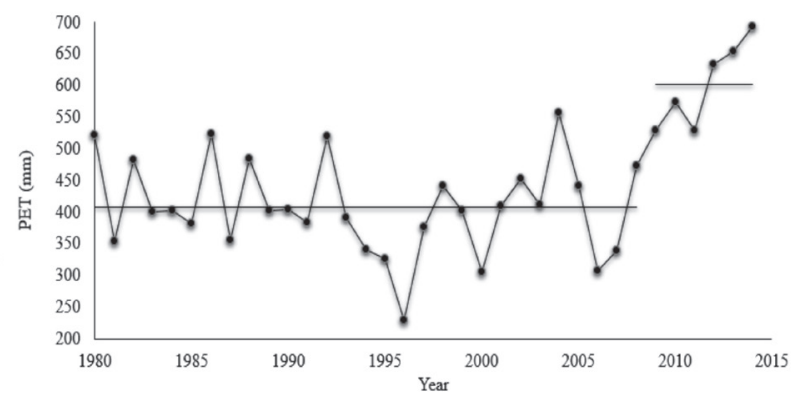

Fig. 4. Pettit test for annual potential evapotranspiration data of Tarbela catchment.

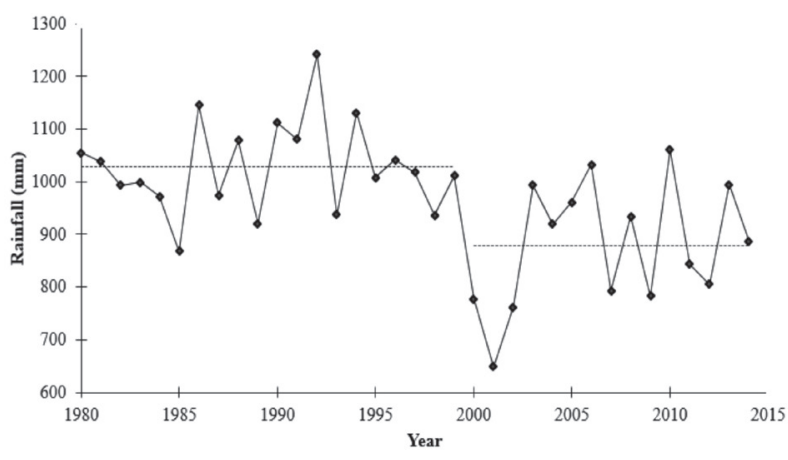

Fig. 5. Pettit test for annual rainfall data of Tarbela catchment.

formula was selected while performing analysis for original climate elasticity method. The attribution results for original climate elasticity method are presented in Table 4, which shows that during 19802014 mean annual precipitation was $964.5 \mathrm{~mm}$, mean annual potential evapotranspiration was $441.5 \mathrm{~mm}$ and the Ep, EPET were calculated using Zhang. The relative contribution of climate change $\Delta \mathrm{Rc}$ and relative contribution of land use change $\Delta \mathrm{RL}$ were calculated using the following formulas:

$$
\begin{aligned}
& \eta_{c}=\frac{\Delta Q_{c}}{\Delta Q} \times 100 \% \\
& \eta_{l}=\frac{\Delta Q_{l}}{\Delta Q} \times 100 \%
\end{aligned}
$$


Table 4. Original climate elasticity method results.

\begin{tabular}{|c|c|c|c|c|c|c|c|c|}
\hline Period & Formula & $\begin{array}{c}\text { P } \\
(\mathrm{mm})\end{array}$ & $\begin{array}{c}\text { PET } \\
(\mathrm{mm})\end{array}$ & $\begin{array}{c}\mathrm{Ep} \\
(\mathrm{mm})\end{array}$ & $\begin{array}{c}\Delta \text { PET } \\
(\mathrm{mm})\end{array}$ & $\begin{array}{c}\Delta \mathrm{Rc} \\
(\mathrm{mm})\end{array}$ & $\begin{array}{c}\Delta \text { Rc } \\
(\%)\end{array}$ & $\begin{array}{c}\Delta \text { RL } \\
(\%)\end{array}$ \\
\hline $1980-2014$ & Zhang(2001) & 964.5 & 441.5 & 0.85 & 0.15 & 38.03 & 39.3 & 60.7 \\
\hline
\end{tabular}

Table 5. Results of improved empirical model of precipitation method.

\begin{tabular}{|c|c|c|c|c|c|c|c|c|}
\hline Period & $\begin{array}{c}* \mathrm{R} 1 \\
(\mathrm{~mm})\end{array}$ & $\begin{array}{c}\text { PET1 } \\
(\mathrm{mm})\end{array}$ & $\begin{array}{c}\text { Rsim1 } \\
(\mathrm{mm})\end{array}$ & $\begin{array}{c}\text { Rsim2 } \\
(\mathrm{mm})\end{array}$ & $\begin{array}{c}\Delta \text { Rc } \\
(\mathrm{mm})\end{array}$ & $\begin{array}{c}\Delta \mathbf{R L} \\
(\mathrm{mm})\end{array}$ & $\begin{array}{c}\Delta \mathrm{Rc} \\
(\%)\end{array}$ & $\begin{array}{c}\Delta \mathbf{R L} \\
(\%)\end{array}$ \\
\hline $1980-2014$ & 434.60 & 423.14 & 438.8 & 394.3 & 40.3 & 56.4 & 41.7 & 58.3 \\
\hline
\end{tabular}

*Here $\mathrm{R}$ represent runoff
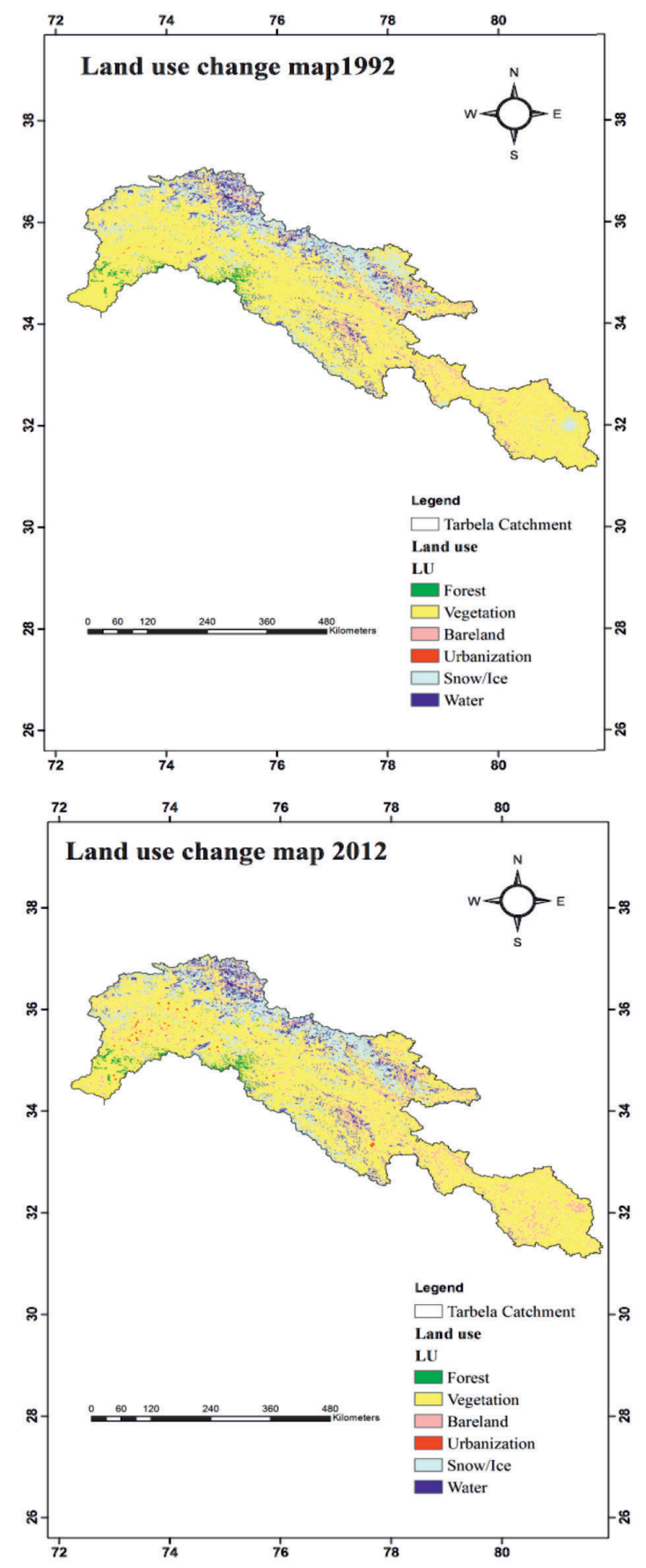

Fig. 6. Land use map of Tarbela catchment in 1992 and 2012.
It can be observed from the results of the improved empirical model of precipitation in Table 5 that both land use and climate change played roles in runoff decrease. The relative contribution of climate change is $39.3 \%$ and relative contribution of land use change is $60.7 \%$. The results of the improved empirical model of precipitation method are presented in Table 5. It can be observed that the change in runoff due to climate change is $40.3 \mathrm{~mm}$ and the change in runoff due to land use change is $56.4 \mathrm{~mm}$. The relative contribution of land use change is $58.3 \%$ and the relative contribution of climate change is $41.7 \%$. These relative contributions are calculated using equations 16 and 17. In these equations, $\mathrm{Cc}$ represents relative contribution of climate change and $\mathrm{CH}$ represents relative contribution of human activities.

\section{Land Use Change and Its Impact on Runoff}

Land use maps of Tarbela catchments are prepared for 1992 and 2012 and these maps are presented in Fig. 6. The land use has been divided into six different classes: forest, vegetation, bare land, urbanization, snow/ice and water. The overall results of land use classification are presented in Table 6. The results show that significant land use changes have been observed in Tarbela catchment. It can be observed that in Tarbela catchment the forest, bare land and snow/glacier area decreased significantly while vegetation and

Table 6. Results of land use classification.

\begin{tabular}{|c|c|c|c|}
\hline \multicolumn{4}{|c|}{ Land use changes $\left(\mathrm{Km}^{2}\right)$ in Tarbela Catchment 1992-2012 } \\
\hline Land use type & 1992 & 2012 & Change (\%) \\
\hline Forest & 14615.37 & 12991.44 & -11.1 \\
\hline Vegetation & 56837.55 & 68205.06 & +20.0 \\
\hline Bare land & 25982.85 & 19487.16 & -25.3 \\
\hline Urbanization & 1623.93 & 3247.86 & +100 \\
\hline Snow/Ice & 61709.34 & 56837.55 & -7.9 \\
\hline Water & 1623.93 & 1623.93 & 0 \\
\hline
\end{tabular}


urbanization increased significantly. The land use maps show that the bare land and glacier area are converted into vegetation. It has been observed in literature [32-34] that the increase in vegetation can be considered as a cause to decrease the runoff as vegetation plays an important role to retain the rainfall water. Therefore, the increase in vegetation in Tarbela catchment can be considered as a significant cause of runoff increase.

\section{Conclusions}

In this study the land use and climate change impacts on streamflow of Tarbela catchment are estimated. The original climate elasticity method and improved empirical model of precipitation, PE and runoff were selected to perform the runoff attribution. The digital elevation model (DEM) was downloaded. The resolution of this DEM is $30 \mathrm{~m}$. In Tarbela catchment the lowest elevation was observed as $361 \mathrm{~m}$ and the highest elevation was observed as $8448 \mathrm{~m}$. The catchment area of Tarbela Dam is poorly gauged and the collected information was available for different time periods. The data stations available with maximum records were selected for hydrological analysis. According to the available information, the FAO guideline is used to calculate the potential evapotranspiration data of the study area. The Mann Kendal test was performed for hydrological trend analysis. The test was performed on rainfall, runoff and potential evapotranspiration series of Tarbela catchment. The test was performed on a data set from 1980-2012. The Mann Kendal test results suggested that the precipitation trends are decreasing in the Tarbela catchment. The results for potential evapotranspiration shows that there is a significant increase in potential evapotranspiration of Tarbela catchment. Similarly, the results for runoff series shows that there is a significant decreasing trend in the runoff series. The Pettit test was performed on rainfall, runoff and potential evapotranspiration series of Tarbela catchment. The test was performed on a data set from 1980-2012. It is observed that for annual rainfall series there is a change point around the year 1999. Moreover, for potential evapotranspiration series there is a change point around 2008. Similarly, for runoff series there is a change point around 1994. For comparison and better understanding the variable series were divided into two periods. Period I is from 19801994 and period II is from 1995-2012. The original climate elasticity method results show that both climate change and land use played roles in runoff decrease. The climate change relative contribution is $39.3 \%$ and land use change relative contribution is $60.7 \%$. The results of the improved empirical model of precipitation method show that the change in runoff due to climate change is $40.3 \mathrm{~mm}$ and the change in runoff due to land use change is $56.4 \mathrm{~mm}$. The land use change relative contribution is $58.3 \%$ and climate change relative contribution is $41.7 \%$. From both methods (the original climate elasticity and improved empirical model of precipitation methods) it is concluded that both land use and climate change are the drivers for runoff reduction in Tarbela catchment. Moreover, the results from the original climate elasticity method and the improved empirical model of precipitation method are consistent. Land use classification has been performed during the pre- and post-change periods. The results of land use classification show that the contribution of land use change is in agreement with results from both models.

\section{Acknowledgements}

The authors acknowledge the Pakistan Meteorology Department (PMD) and Water and Power Development Authority (WAPDA) Pakistan for providing data for this research.

\section{Conflict of Interest}

The authors declare no conflict of interest.

\section{References}

1. LIU J., YANG H., GOSLING S.N., KUMMU M., FLÖRKE M., PFISTER S., HANASAKI N., WADA Y., ZHANG X., ZHENG C., ALCAMO J., OKI T. Water scarcity assessments in the past, present, and future, Earth's Future, 5, 2017.

2. SHAHID M., CONG Z., ZHANG D. Understanding the impacts of climate change and human activities on streamflow: a case study of the Soan River basin, Pakistan, Theoretical and Applied Climatology, 134, 2018.

3. WANG R., KALIN L., KUANG W., TIAN H. Individual and combined effects of land use/cover and climate change on Wolf Bay watershed streamflow in southern Alabama, Hydrological Processes, 28, 2014.

4. RASHID M., SHAOFENG J. Assessment of hydroclimatic trends and causes of dramatically declining stream flow to Lake Chad, Africa, using a hydrological approach, Science of The Total Environment, 675, 2019.

5. STOCKER T., QIN D., PLATTNER G., TIGNOR M., ALLEN S., BOSCHUNG J., NAUELS A., XIA Y., BEX V., MIDGLEY P. IPCC, 2013: Climate Change 2013: The Physical Science Basis. Contribution of Working Group I to the Fifth Assessment Report of the Intergovernmental Panel on Climate Change, 1535 pp: Cambridge Univ. Press, Cambridge, UK, and New York, 2013.

6. ZHU X., LIU W., JIANG X.J., WANG P., LI W. Effects of land-use changes on runoff and sediment yield: Implications for soil conservation and forest management in Xishuangbanna, Southwest China, Land Degradation \& Development 29, 2018.

7. JAKEMAN A.J., BARRETEAU O., HUNT R.J., RINAUDO J.-D. \& ROSS A. Integrated Groundwater Management: Concepts, Approaches and Challenges, Cham: Springer International Publishing, 2016.

8. LI R., ZHENG H., HUANG B., HUASHAN X., LI Y. Dynamic Impacts of Climate and Land-Use Changes on 
Surface Runoff in the Mountainous Region of the Haihe River Basin, China, Advances in Meteorology, 10, 2018.

9. WANG H., STEPHENSON S.R. Quantifying the impacts of climate change and land use/cover change on runoff in the lower Connecticut River Basin, Hydrological Processes, 32, 2018.

10. BAI P., LIU W., GUO M. Impacts of climate variability and human activities on decrease in streamflow in the Qinhe River, China, Theoretical and applied climatology, 117, 2014

11. MAHMOOD R., BABEL M.S. Evaluation of SDSM developed by annual and monthly sub-models for downscaling temperature and precipitation in the Jhelum basin, Pakistan and India, Theoretical and Applied Climatology, 113, 2013.

12. TRAIL M., TSIMPIDI A.P., LIU P., TSIGARIDIS K., HU Y., NENES A., STONE B., RUSSELL A.G. Potential impact of land use change on future regional climate in the Southeastern US: reforestation and crop land conversion, Journal of Geophysical Research: Atmospheres, 118, 2013.

13. GAO L., ZHANG Y. Spatio-temporal variation of hydrological drought under climate change during the period 1960-2013 in the Hexi Corridor, China, Journal of Arid Land, 8, 2016.

14. DU C., SUN F., YU J., LIU X., CHEN Y. New interpretation of the role of water balance in an extended Budyko hypothesis in arid regions, Hydrology and Earth System Sciences, 20, 2016.

15. DU J., QIAN L., RUI H., ZUO T., ZHENG D., XU Y., C $Y$ XU. Assessing the effects of urbanization on annual runoff and flood events using an integrated hydrological modeling system for Qinhuai River basin, China, Journal of Hydrology ,464, 2012.

16. IDA B., SONNENBORG., TORBEN O., REFSGAARD., JENS C., TROLLE., DENNIS., BØRGESEN., CHRISTEN D., OLESEN., JEPPESEN.,. ERIK., JEPPESEN ., KARSTEN H. Combined effects of climate models, hydrological model structures and land use scenarios on hydrological impacts of climate change, Journal of Hydrology, 535, 2016.

17. LI S., XIONG L., LI H Y., LEUNG L.R., DEMISSIE Y. Attributing runoff changes to climate variability and human activities: uncertainty analysis using four monthly water balance models, Stochastic environmental research and risk assessment, 30, 2016.

18. ZHANG L., NAN Z., XU Y., LI S. Hydrological impacts of land use change and climate variability in the headwater region of the Heihe River Basin, Northwest China, PloS one, 11, 2016.

19. HE Y., LIN K., CHEN X. Effect of land use ad climate change on runoff in the Dongjiang basin of South China, Mathematical problems in Engineering, 14, 2013.

20. YAN R., CAI Y., LI C., WANG X., LIU Q. Hydrological response to climate and land use changes in a watershed of the Loess Plateau, China, Sustainbility, 11, 2019.
21. SHAHID M., GABRIEL H.F., NABI A., HAIDER S., KHAN A., SHAH A. Evaluation of development and land use change effects on rainfall-runoff and runoff-sediment relations of catchment area of Simly Lake Pakistan, Life Science Journal, 11, 2014.

22. TAN X., GAN T.Y., Contribution of human and climate change impacts to changes in streamflow of Canada, Scientific reports, 5, 2015.

23. GAO G., FU B., WANG S., LIANG W., JIANG X. Determining the hydrological responses to climate variability and land use/cover change in the Loess Plateau with the Budyko framework. Science of the Total Environment. 557, 2016.

24. ECKSTEIN D., KÜNZEL V., SCHÄFER L. Global Climate Risk Index 2018, Bonn, Germany: Germanwatch, 2017.

25. MWANGI H., JULICH S., SOPAN D.P., MCDONALD M. A., FEGER K.-H. Relative contribution of land use change and climate variability on discharge of upper Mara River, Kenya, Journal of Hydrology: Regional Studies, 5, 2016.

26. SREELASH K., SHARMA R.K., GAYATHRI J.A., UPENDRA B., MAYA K., PADMALAL D. Impact of Rainfall Variability on River Hydrology: A Case Study of Southern Western Ghats, India, Journal of the Geological Society of India, 92, 2018.

27. ZHANG T., WANG Y., WANG B., FENG P. Understanding the Main Causes of Runoff Change by Hydrological Modeling: A Case Study in Luanhe River Basin, North China, Water, 10, 2018.

28. ATTA-UR-RAHMAN, DAWOOD M. Spatio-statistical analysis of temperature fluctuation using Mann-Kendall and Sen's slope approach, Climate Dynamics, 48, 2017.

29. BOUAZIZ M., EISOLD S., GUERMAZI E. Semiautomatic approach for land cover classification: a remote sensing study for arid climate in southeastern Tunisia, EuroMediterranean Journal for Environmental Integration, 2, 2017.

30. PANDE C.B., MOHARIR K.N., KHADRI S.F.R., PATIL S. Study of land use classification in an arid region using multispectral satellite images, Applied Water Science, 18, 2018.

31. JAISWAL RK., LOHANI AK., TIWARI HL. Statistical Analysis for Change Detection and Trend Assessment in Climatological Parameters, Environmental Processes, 2, 2015.

32. XIONG L., JIANG C., XU C.Y., YU K.X., GUO S. A framework of change-point detection for multivariate hydrological series, Water Resources Research, 51, 2015.

33. WANG J., LI Z., YAO W., DONG G. Influence of vegetation on runoff and sediment in wind-water erosion crisscross region in the upper Yellow River of China, Chinese Geographical Science, 27, 2017.

34. YANG C.X., XIAO P., LI L., JIAO P. Effect of vegetation construction on runoff and sediment yield and runoff erosion ability on slope surface, E3S Web Conf, 2018. 